\title{
Analysis of the Mitogen-activated protein kinase kinase 4 (MAP2K4) tumor suppressor gene in ovarian cancer
}

\author{
Sally J Davis ${ }^{1,2}$, David YH Choong ${ }^{1}$, Manasa Ramakrishna ${ }^{1,2}$, Georgina L Ryland ${ }^{1,3}$, lan G Campbell ${ }^{1,2+}$ and \\ Kylie L Gorringe ${ }^{1,2^{*}+}$
}

\begin{abstract}
Background: MAP2K4 is a putative tumor and metastasis suppressor gene frequently found to be deleted in various cancer types. We aimed to conduct a comprehensive analysis of this gene to assess its involvement in ovarian cancer.

Methods: We screened for mutations in MAP2K4 using High Resolution Melt analysis of 149 primary ovarian tumors and methylation at the promoter using Methylation-Specific Single-Stranded Conformation Polymorphism analysis of 39 tumors. We also considered the clinical impact of changes in MAP2K4 using publicly available expression and copy number array data. Finally, we used siRNA to measure the effect of reducing MAP2K4 expression in cell lines.
\end{abstract}

Results: In addition to 4 previously detected homozygous deletions, we identified a homozygous 16 bp truncating deletion and a heterozygous 4 bp deletion, each in one ovarian tumor. No promoter methylation was detected. The frequency of MAP2K4 homozygous inactivation was $5.6 \%$ overall, and $9.8 \%$ in high-grade serous cases. Hemizygous deletion of MAP2K4 was observed in 38\% of samples. There were significant correlations of copy number and expression in three microarray data sets. There was a significant correlation between MAP2K4 expression and overall survival in one expression array data set, but this was not confirmed in an independent set. Treatment of JAM and HOSE6.3 cell lines with MAP2K4 siRNA showed some reduction in proliferation.

Conclusions: MAP2K4 is targeted by genetic inactivation in ovarian cancer and restricted to high grade serous and endometrioid carcinomas in our cohort.

\section{Background}

Mitogen-activated protein kinase kinase 4 (MAP2K4) is a gene encoding a member of the MAP kinase signalling family $[1,2]$. This 399 amino acid protein is a component of a triple kinase cascade whereby activated MAP kinases are successively phosphorylated to mediate cellular responses to cytokine signals, stress and other extracellular stimuli [3]. The phosphorylation cascade is initiated by the activation of MAP3K proteins, such as MEKK and MLK, which phosphorylate MAP2K4. In its activated state, MAP2K4 can phosphorylate JNK or p38

\footnotetext{
* Correspondence: kylie.gorringe@petermac.org

+ Contributed equally

'VBCRC Cancer Genetics Laboratory, Peter MacCallum Cancer Centre, St.

Andrew's Pl., East Melbourne, Victoria, Australia

Full list of author information is available at the end of the article
}

with dual specificity, resulting in the activation of the stress activated protein kinase (SAPK) pathway, which has been associated with apoptosis and neoplastic transformation $[4,5]$. However, the response initiated through the activation of JNK or p38 appears to be highly context dependent. For example, prolonged JNK activation has been demonstrated to induce an apoptotic effect in certain neuronal cells independent of c-Jun [6,7]. However, transient JNK activation in response to physiological stimuli does not elicit neuronal apoptosis, reflecting a dependence upon other factors to activate the JNKmediated apoptotic pathway [8].

The genetic evidence for a role of MAP2K4 in cancer is gathering strength. It was initially described as a tumor suppressor gene (TSG), with a low frequency of

\section{Biomed Central}

(c) 2011 Davis et al; licensee BioMed Central Ltd. This is an Open Access article distributed under the terms of the Creative Commons Attribution License (http://creativecommons.org/licenses/by/2.0), which permits unrestricted use, distribution, and reproduction in any medium, provided the original work is properly cited. 
deletions and mutations reported in a variety of cancer types [9]. In recent high-throughput sequencing and copy number studies, MAP2K4 appears to be only very rarely targeted by base pair level mutation but is consistently identified as a common target for deletion, including homozygous deletion [10-12]. While some of these deletions may be a consequence of $\mathrm{LOH}$ targeting the nearby TP53 gene on 17q12, in a few instances there are homozygous deletions that appear to target only MAP2K4. Despite this genetic support for a tumor suppressor role, functional studies have generated mixed results. One experimental model demonstrated that overexpression of MAP2K4 could reduce the incidence and onset of metastasis in ovarian and prostate cancer cell lines [13]. However, in contrast, overexpression and silencing of the gene in a different cellular context was found to support a pro-oncogenic role for MAP2K4 [14].

In ovarian cancer, in addition to the apparent role of MAP2K4 in metastasis suppression, there have been limited data showing loss of expression and genetic aberrations in several small cohorts [15-17]. Gene expression by immunohistochemistry and quantitative PCR was found to be reduced in cancer samples compared to normal or benign ovarian tissue. The only study to examine epigenetic control of MAP2K4 in any cancer type was performed on a small number of ovarian cancer cases, and did not find any evidence for promoter methylation [16]. We have previously reported that recurrent homozygous deletions appear to specifically target MAP2K4 in primary ovarian tumors, and the gene lay in a minimal region of loss of heterozygosity $(\mathrm{LOH})$ in $68 \%(72 / 106)$ of the cases, the second most frequent locus targeted by $\mathrm{LOH}$ [18]. Despite this accumulating evidence, the status of $M A P 2 K 4$ as a tumor suppressor in ovarian cancer is equivocal and therefore in this study we have undertaken a comprehensive analysis of mutation, methylation and gene knockdown.

\section{Methods}

\section{Clinical specimens}

One hundred and sixty one tumor tissue samples (77 serous, 21 mucinous, 33 endometrioid, 8 clear cell and 22 other, Additional file 1, Table S1) were obtained from patients presenting to hospitals in the south of England, UK or at the Peter MacCallum Cancer Centre, Australia. DNA was extracted either from whole tissue or from samples that were manually needle microdissected to ensure they contained $>85 \%$ epithelial tumor cells. RNA was extracted from microdissection of subsequent $10 \mu \mathrm{m}$ sections using the mirVana miRNA Isolation Kit (Ambion Inc, Austin, TX). Normal DNA was extracted from matching peripheral blood samples as described previously [19]. DNA for mutation screening underwent whole genome amplification (WGA) using the Repli-G Phi-mediated amplification system as described previously [20]. Institutional ethics committees approved this study.

\section{Mutation screening of MAP2K4 using High Resolution Melt (HRM)}

Primers were designed to amplify each exon and the intron/exon boundaries of the MAP2K4 coding sequence using the software packages ExonPrimer and Primer3 [21], except for exon 11, which used previously published primers [12]. Exon 7 was covered by two overlapping primer pairs. Exon 1 was not analyzed as the PCR could not be optimized to amplify a specific product, despite multiple different primer sets, most likely because of the high GC content. Exon 1 contains 114 bp of coding sequence and has similarly been excluded from other mutation screening studies [12,22]. Primer sequences and amplification conditions are listed in Additional file 2, Table S2. HRM using PCR products amplified from WGA template DNA and DNA sequencing were carried out as described previously [20]. Somatic alterations were confirmed by re-sequencing from non-WGA tumor DNA and the matching normal DNA.

\section{MAP2K4 promoter methylation analysis by Methylation- Specific Single Strand Conformation Polymorphism (MS- SSCP) and bisulfite sequencing}

The MAP2K4 CpG island was amplified using previously published oligonucleotides [16]. DNA samples were bisulphite treated using the MethylEasy Xceed Rapid DNA Bisulphite Modification kit (Human Genetic Signatures, Sydney, Australia) following the manufacturer's instructions. After PCR amplification, products were analyzed by SSCP using the ABI 3130 Genetic Analyzer (Applied Biosystems, Foster City, CA) as described previously [20], with SssI methylase-treated normal DNA used as a positive control for $\mathrm{CpG}$ island methylation. Normal DNA samples were treated using CpG methyltransferase SssI (New England Biolabs, Ipswich, MA), which methylates all CpGs before bisulfite treatment. Samples showing a shift in mobility were sequenced as described above.

\section{Knock-down of MAP2K4 in cell culture}

Reagents for transient gene knockdown were obtained from Dharmacon (Thermo Fisher Scientific, Lafayette, $\mathrm{CO}$ ), comprising the siRNA SMARTpools for MAP2K4 (L-003574-00) and a non-targeting control siRNA (D-001810-0X). This analysis was performed using the JAM and HOSE6.3 ovarian cell lines. The JAM cell line is a derivative of a poorly differentiated serous cystadenocarcinoma [23], while the HOSE6.3 cell line has been established by E6/E7 immortalisation of human ovarian surface epithelial cells [24]. 
Cells were cultured in 96-well plates at an initial density of $3.0 \times 10^{3}$ per well. Each cell line was reverse transfected [25] with $25 \mathrm{nmol} / \mathrm{l}$ of siRNA and the appropriate transfection reagent diluted in Optimem ${ }^{\circledR}$ serum free medium (Invitrogen, Carlsbad, CA). HOSE 6.3 was treated with $0.05 \mu$ l DharmaFECT 1 and JAM was treated with $0.1 \mu \mathrm{l}$ DharmaFECT 3. All transfections were performed in triplicate and in three separate experiments.

Transfection efficiency was determined by quantitative PCR (QPCR) whereby RNA was extracted from cells at $48 \mathrm{~h}$ post-transfection using the RNeasy Mini kit (Qiagen, Valencia, CA, USA), in accordance with the manufacturer's instructions. Thereafter, cDNA was generated from 100 ng of RNA using Superscript III VILO (Invitrogen, Carlsbad, CA), in accordance with the manufacturer's instructions. Expression of MAP $2 K 4$ was assessed using primers listed in Additional file 2, Table S2 on the LightCycler ${ }^{\circledR} 480$ (Roche Diagnostics, Mannheim, Germany). PCR was performed using the SYBRgreen QPCR mix (Thermo Fisher Scientific, Lafayette, $\mathrm{CO}$ ) and relative $M A P 2 K 4$ gene expression was determined according to the comparative $C_{\mathrm{T}}\left(\Delta \Delta \mathrm{C}_{\mathrm{T}}\right)$ method: $\Delta \Delta \mathrm{C}_{\mathrm{T}}=\Delta \mathrm{C}_{\mathrm{T}}$ $M A P 2 K 4$ siRNA DNA $-\Delta \mathrm{C}_{\mathrm{T}}$ Non-targeting siRNA DNA. $\Delta \mathrm{C}_{\mathrm{T}}$ (threshold cycles) is the $\mathrm{C}_{\mathrm{T}}$ of the reference gene minus the $\mathrm{C}_{\mathrm{T}}$ of the target gene. Fold difference of $M A P 2 K 4$ expression was calculated by $2^{-\Delta \Delta C T}$. Hypoxanthine phosphoribosyltransferase 1 (HPRT1) was used as an endogenously expressed reference gene for the purpose of quantifying relative gene expression. Each QPCR was performed in triplicate using cDNA derived from three independent experiments. Cellular proliferation was measured across a 7-day period according to the reduction of alamarBlue reagent (Invitrogen, Calsbad, CA) following a $4 \mathrm{~h}$ incubation as described previously [26].

\section{Statistical Analysis}

Expression array files were imported into Partek Genomics Suite v 6.4 (Partek, St. Louis, MO) using default parameters including RMA normalization. These values were then used for statistical tests. Cox regression analysis was carried out in Partek Genomics Suite v 6.4. The results published here are in part based upon data generated by The Cancer Genome Atlas pilot project established by the NCI and NHGRI. Information about TCGA and the investigators and institutions who constitute the TCGA research network can be found at http://cancergenome.nih.gov. Other statistical analyses were carried out using GraphPad Prism software v5 (GraphPad Software, La Jolla, CA) and were considered significant at a $\mathrm{P}$-value of less than 0.05 . In assessing differences in proliferation, 2-way ANOVA was performed to interrogate time points as categorical variables.

\section{Results and Discussion}

We previously reported $M A P 2 K 4$ as a candidate tumor suppressor gene [18] after SNP array copy number and LOH data from 125 primary ovarian tumors identified four homozygous deletions with a minimal point of overlap of just $50 \mathrm{~kb}$, which targeted two genes, $M A P 2 K 4$ and hsa-mir-744. In the current study we decided to undertake further analysis of these genes to assess the frequency of gene inactivation by means other than deletion (the analysis of hsa-mir-744 will be described elsewhere). We analyzed exons 2-11 of $M A P 2 K 4$ in 149 primary ovarian cancers using HRM and DNA sequencing. We identified two somatic alterations, a homozygous 16 bp deletion in exon 7 in a serous ovarian tumor (Figure 1), and a heterozygous 4 bp deletion in exon 3 in an endometrioid tumor. The 16 bp deletion in IC489 causes a frameshift alteration that would lead to protein termination 7 amino acids downstream (p.Asp263fs). The mutation represented more than $70 \%$ of the bases in the sequence trace, thus we consider it to be homozygous, correlating with the SNP array data for this tumor showing chromosome $17 \mathrm{LOH}$ across the $M A P 2 K 4$ locus. The 4 bp deletion at the start of exon 3 would cause protein termination two amino acids downstream (p.Glu74fs) and is heterozygous in accordance with the lack of LOH at the locus in IC128 by SNP array.

No known or novel polymorphisms were detected in the coding region of $M A P 2 K 4$, which is consistent with the low number $(\mathrm{n}=5)$ of reported coding variants (dbSNP build 130, http://www.ncbi.nlm.nih.gov/projects/ $\mathrm{SNP} /$ ). Consequently, the failure to detect variants should not be attributed to a deficiency in the accuracy of the method, which has been successfully utilised to detect both novel and previously described polymorphisms in a similar context [20,27].

Combining the detection of mutation and deletion data, the overall frequency of homozygous inactivation of $M A P 2 K 4$ was $5.6 \%$ (5/89 samples analysed by both techniques). However, it was notable that cases with genetic changes were either of the high-grade serous $(4 / 5)$ or grade 3 endometrioid (1/5) subtypes. As a proportion of these subtypes, inactivation of $M A P 2 K 4$ was $9.8 \%(4 / 41)$ and $4.8 \%(1 / 21)$, respectively. We also analyzed copy number data from The Cancer Genome Atlas (TCGA), a public data set of mostly high-grade serous ovarian tumors (http://cancergenome.nih.gov). In 157 SNP6.0 arrays, we identified a further 3 homozygous deletions, two of which specifically targeted only $M A P 2 K 4$. TCGA has undertaken mutation screening by sequencing on 24 samples to date with no somatic alterations identified.

We had previously observed a decrease in MAP2K4 RNA expression in samples with $\mathrm{LOH}$ at the locus [18]. 


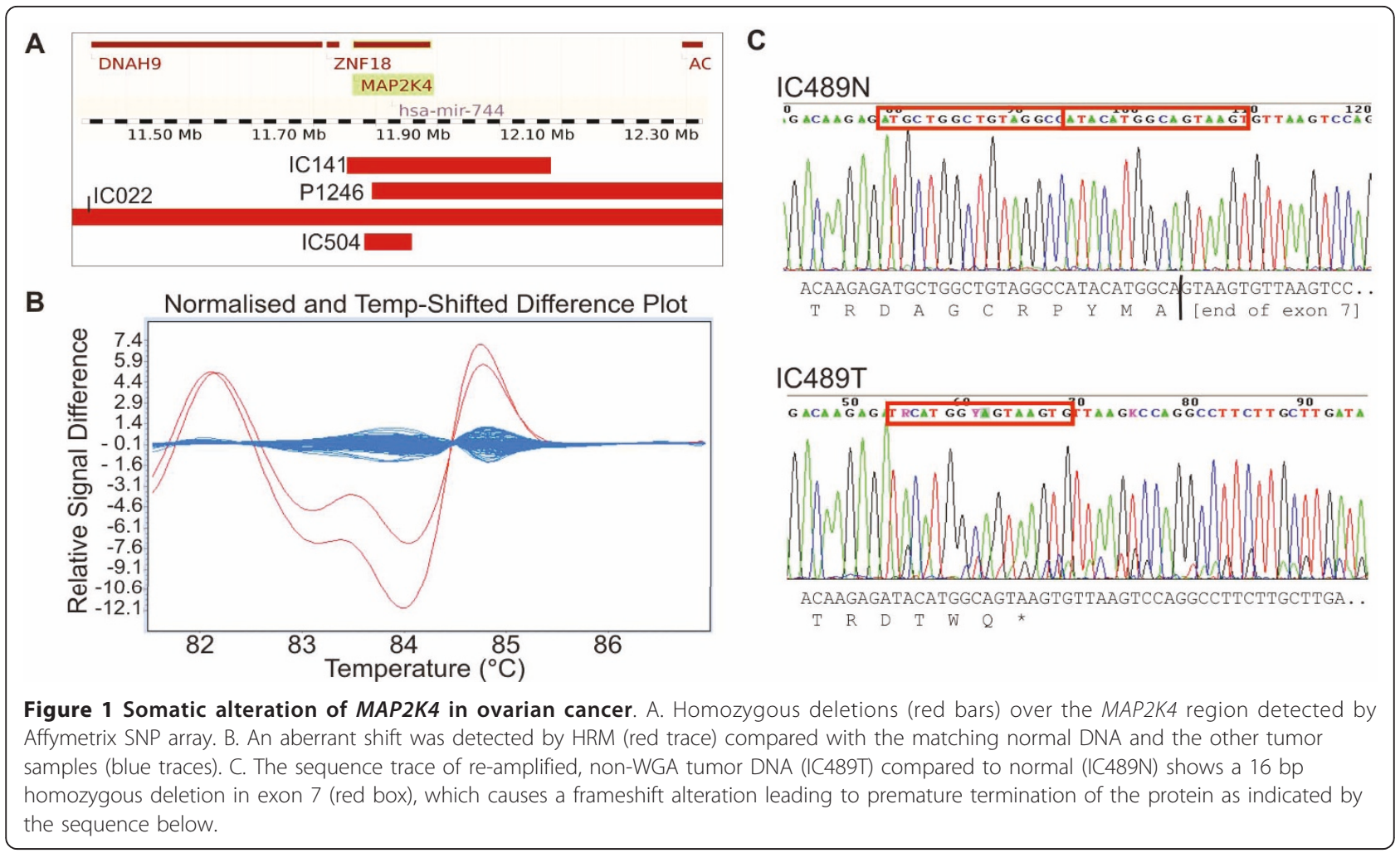

We analyzed promoter methylation by MS-SSCP and bisulfite sequencing to assess whether this reduction in expression was mediated by epigenetic mechanisms (Figure 2). We did not detect any electrophoretogram shifts in any tumor DNA that would indicate methylation in this region, in contrast to the positive SssI treated control DNA. This was confirmed by selecting a few samples for sequencing. Consequently, methylation does not appear to be a mechanism by which MAP $2 K 4$ is silenced in ovarian cancer. In contrast, there was a high proportion of samples exhibiting $\mathrm{LOH}$ in conjunction with copy number loss at the MAP2K4 locus [18]. 56\% of samples with $\mathrm{LOH}$ ( $38 \%$ of samples overall) were subject to copy number loss, indicating that MAP $2 K 4$ may be targeted by this genetic mechanism. In a recent copy number analysis [28] we found that 164/398 (41\%) ovarian carcinomas of primarily serous/endometrioid subtype showed at least hemizygous copy number loss at $M A P 2 K 4$. In addition, there was a strong correlation between copy number and gene expression in three microarray data sets of high grade serous/endometrioid ovarian carcinoma (Additional file 3, Figure S1): our own ([29]; $\mathrm{r}=0.46, \mathrm{p}=0.001, \mathrm{n}=47$ ), Etemadmoghadam et al., ([30]; $\mathrm{r}=0.59, \mathrm{p}<0.0001, \mathrm{n}=79)$, and TCGA $(\mathrm{r}=0.51, \mathrm{p}<0.0001, \mathrm{n}=157)$. Therefore, the loss of MAP2K4 expression may be largely attributable to genomic loss, rather than epigenetic mechanisms of gene regulation.
To assess the impact of reduced MAP2K4 expression we used the full TCGA data ( $\mathrm{n}=400$ with outcome data) and another published data set $([31], \mathrm{n}=207)$ to investigate any association with clinical outcome in invasive ovarian carcinoma (Additional file 4, Figure S2). Both data sets were comprised of primarily high-grade serous carcinomas. In a Cox regression analysis including age and residual disease as co-factors in the model, low expression of MAP2K4 was associated with improved overall survival in the Tothill data set $(\mathrm{P}=$ 0.031 , hazards ratio $=1.7)$, but was not significant in the TCGA data set $(\mathrm{P}=0.75)$. Expression of MAP2K4 was not significant in either data set when progression free survival was considered. When viewing this data using a Kaplan-Meier plot having split the samples based on quartiles of expression values, the difference in survival was associated only with the bottom quartile (low expressors) in the Tothill data set.

To measure the effect of reduced MAP2K4 expression, we knocked down MAP2K4 in two cell lines using siRNA and assessed cellular proliferation (Figure 3). We used an immortalized cell line derived from human ovarian surface epithelium (HOSE6.3 [24]). While this line is not normal, it is non-tumorigenic and should have fewer disrupted pathways or additional genetic lesions than the cancer cell lines used previously. For comparison, we selected a cell line established in culture from an ovarian tumor xenograft, JAM [23], which 


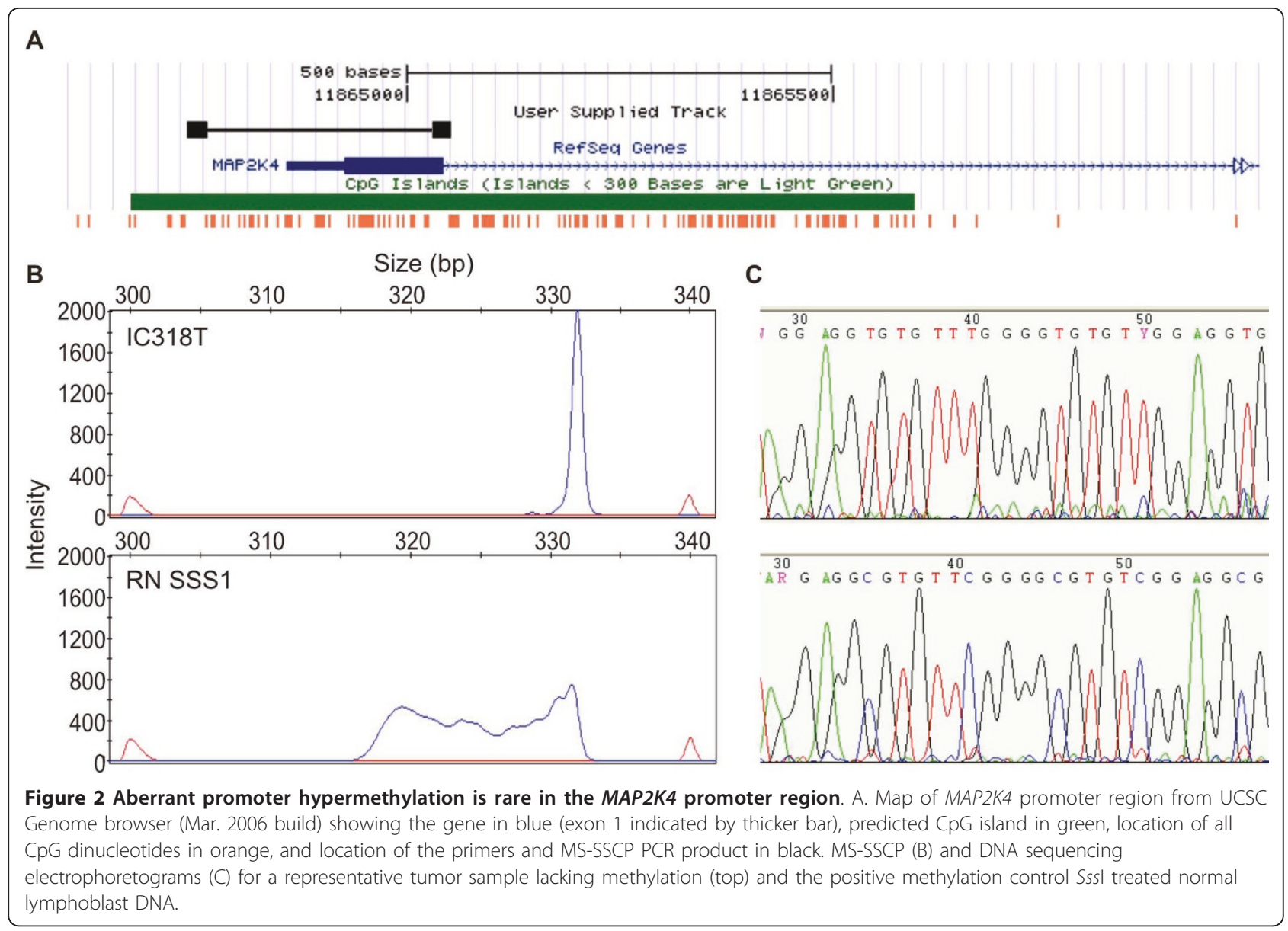

A

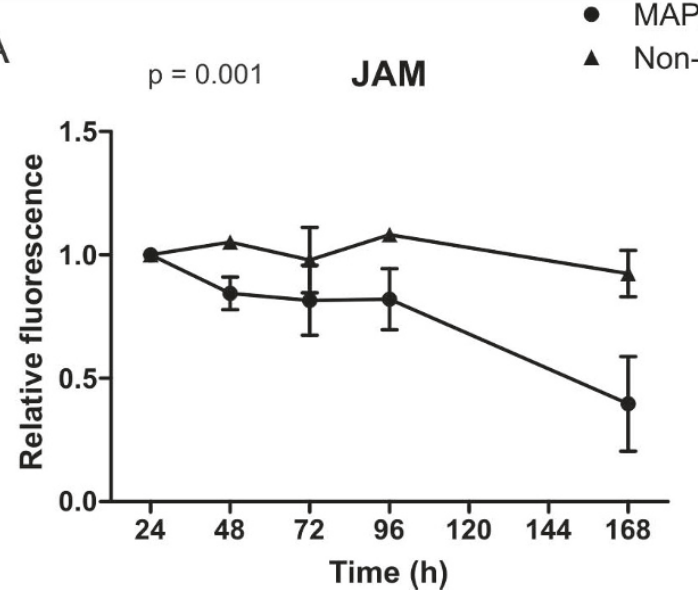

- MAP2K4 siRNA

Non-targeting siRNA

HOSE6.3 $p=0.12$

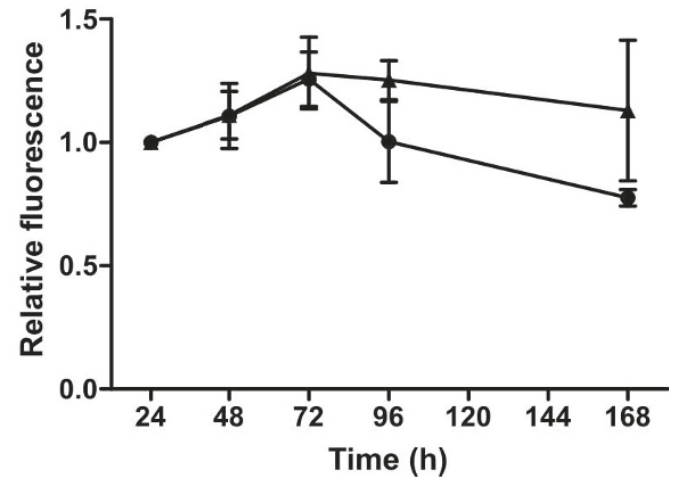

Figure 3 Loss of MAP2K4 expression affects cellular proliferation. Cellular proliferation was assessed using alamarBlue dye measured by fluorescence at 540/610 $\mathrm{nm}$. Each of three experiments was performed in triplicate and normalized to the $24 \mathrm{~h}$ time-point. The average of three biological replicates is shown, except for the $168 \mathrm{~h}$ time-point, which was only done twice. Statistical significance was determined by 2-way ANOVA. Error bars are representative of SEM, $\mathrm{n}=3$. 
expresses high levels of MAP2K4. Expression of $M A P 2 K 4$ in transfected cells was evaluated at $48 \mathrm{~h}$ posttransfection by QPCR in each of the assays performed (Additional file 5, Figure S3). In each case, highly efficient gene silencing was observed, with at least $75 \%$ silencing of MAP2K4 expression in both cell lines analyzed. Cellular proliferation and metabolism was measured across a seven-day period. Both JAM and HOSE6.3 showed some reduction in cell number over this time course in the cells treated with MAP2K4 siRNA, however this was only significant for the JAM cells ( $\mathrm{P}=0.001,2$-way ANOVA). A recent study used a stable RNAi system to knock down expression of $M A P 2 K 4$, and was able to select clones with reduced $M A P 2 K 4$ expression, suggesting that loss of the gene may not always adversely affect cell viability or proliferation [32]. In this system the study found that MAP2K4 inactivation correlated with increased invasiveness through the induction of the epithelial to mesenchymal transition (EMT). Another recent study found that ectopic expression of MAP2K4 mutants increased anchorage-independent growth in NIH3T3 cells [33]. The effect of MAP2K4 gene knockdown may therefore be dependent on the in vitro experimental system used, perhaps not surprisingly given the role of the protein in such a complex signalling network.

\section{Conclusions}

In summary, we have conducted a comprehensive analysis of mutation, methylation, expression and gene knockdown of MAP2K4 in ovarian cancer. We did not detect any methylation at the MAP2K4 promoter in ovarian tumour tissue, consistent with one other study to date [16]. We did find genetic alterations confirming MAP2K4 as a tumour suppressor gene for ovarian cancer in a subset of high grade serous and endometrioid cases, including a specific 16 bp homozygous deletion in exon 7 as well as larger homozygous deletions. In addition, we found that $M A P 2 K 4$ was frequently targeted by hemizygous deletion and that this correlated with decrease in gene expression in several independent ovarian cancer data sets.

\section{Additional material}

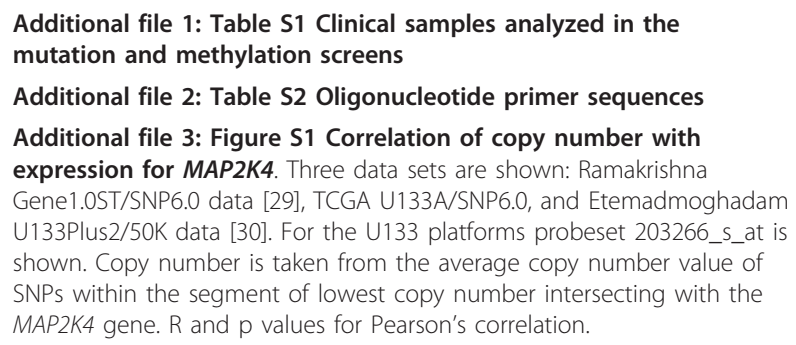

Additional file 4: Figure S2 Overall survival of ovarian cancer patients relative to MAP2K4 expression. A. Partek output for Cox regression analysis in the Tothill data set of MAP2K4 expression probeset 203266_s_at, including patient age and residual disease as co-factors. B. Kaplan-Meier curves, showing difference in survival of patients with low MAP2K4 expression (bottom quartile of cases, red solid line) compared to all remaining cases (blue dashed line) from Tothill et al., 2008 and The Cancer Genome Atlas (TCGA). Graphs truncated at 150 months. P value shown is the log rank (Mantel-Cox) test.

Additional file 5: Figure S3 Reduction in MAP2K4 expression following siRNA knockdown

\section{Acknowledgements}

This study was funded by the Victorian Breast Cancer Research Consortium, Australia (VBCRC) and the Australian National Health and Medical Research Council (NHMRC). MR is supported by a Cancer Council of Victoria Postgraduate Scholarship. GLR is supported by an Australian Postgraduate Award.

\section{Author details}

${ }^{1}$ VBCRC Cancer Genetics Laboratory, Peter MacCallum Cancer Centre, St. Andrew's Pl., East Melbourne, Victoria, Australia. ${ }^{2}$ Department of Pathology, University of Melbourne, Parkville, Victoria, Australia. ${ }^{3}$ Centre for Cancer Research, Monash Institute of Medical Research, Monash University, Clayton, Victoria, Australia.

\section{Authors' contributions}

IGC and KLG conceived of the study, participated in its design and coordination and helped to draft the manuscript. SJD performed the mutation, methylation and functional analyses and drafted the manuscript. DYHC and GLR assisted in the mutation and methylation analyses. MR assisted in the functional analyses. All authors read and approved the final manuscript.

\section{Competing interests}

The authors declare that they have no competing interests.

Received: 24 August 2010 Accepted: 17 May 2011

Published: 17 May 2011

\section{References}

1. Chang L, Karin M: Mammalian MAP kinase signalling cascades. Nature 2001, 410(6824):37-40.

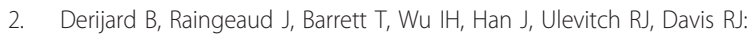
Independent human MAP-kinase signal transduction pathways defined by MEK and MKK isoforms. Science 1995, 267(5198):682-685.

3. Johnson GL, Lapadat R: Mitogen-activated protein kinase pathways mediated by ERK, JNK, and p38 protein kinases. Science 2002, 298(5600):1911-1912.

4. Davis RJ: Signal transduction by the JNK group of MAP kinases. Cell 2000, 103(2):239-252.

5. Ip YT, Davis RJ: Signal transduction by the c-Jun N-terminal kinase (JNK)from inflammation to development. Curr Opin Cell Biol 1998, 10(2):205-219.

6. Xia Z, Dickens M, Raingeaud J, Davis RJ, Greenberg ME: Opposing effects of ERK and JNK-p38 MAP kinases on apoptosis. Science 1995, 270(5240):1326-1331.

7. Yang D, Tournier C, Wysk M, Lu HT, Xu J, Davis RJ, Flavell RA: Targeted disruption of the MKK4 gene causes embryonic death, inhibition of cJun NH2-terminal kinase activation, and defects in AP-1 transcriptional activity. Proc Natl Acad Sci USA 1997, 94(7):3004-3009.

8. Xu X, Raber J, Yang D, Su B, Mucke L: Dynamic regulation of C-Jun Nterminal kinase activity in mouse brain by environmental stimuli. Proc Natl Acad Sci USA 1997, 94(23):12655-12660.

9. Teng DH, Perry WL, Hogan JK, Baumgard M, Bell R, Berry S, Davis T, Frank D, Frye C, Hattier T, Hu R, Jammulapati S, Janecki T, Leavitt A, Mitchell JT, Pero R, Sexton D, Schroeder M, Su PH, Swedlund B, Kyriakis JM, Avruch J, Bartel P, Wong AK, Tavtigian SV, et al: Human mitogen-activated protein 
kinase kinase 4 as a candidate tumor suppressor. Cancer Res 1997, 57(19):4177-4182.

10. Beroukhim R, Mermel CH, Porter D, Wei G, Raychaudhuri S, Donovan J, Barretina J, Boehm JS, Dobson J, Urashima M, Mc Henry KT, Pinchback RM, Ligon AH, Cho YJ, Haery L, Greulich H, Reich M, Winckler W, Lawrence MS, Weir BA, Tanaka KE, Chiang DY, Bass AJ, Loo A, Hoffman C, Prensner J, Liefeld T, Gao Q, Yecies D, Signoretti S, et al: The landscape of somatic copy-number alteration across human cancers. Nature 2010, 463(7283):899-905

11. Leary RJ, Lin JC, Cummins J, Boca S, Wood LD, Parsons DW, Jones S, Sjoblom T, Park BH, Parsons R, Willis J, Dawson D, Willson JK, Nikolskaya T, Nikolsky Y, Kopelovich L, Papadopoulos N, Pennacchio LA, Wang TL, Markowitz SD, Parmigiani G, Kinzler KW, Vogelstein B, Velculescu VE: Integrated analysis of homozygous deletions, focal amplifications, and sequence alterations in breast and colorectal cancers. Proc Natl Acad SCi USA 2008, 105(42):16224-16229.

12. Sjoblom T, Jones S, Wood LD, Parsons DW, Lin J, Barber TD, Mandelker D, Leary RJ, Ptak J, Silliman N, Szabo S, Buckhaults P, Farrell C, Meeh P, Markowitz SD, Willis J, Dawson D, Willson JK, Gazdar AF, Hartigan J, Wu L, Liu C, Parmigiani G, Park BH, Bachman KE, Papadopoulos N, Vogelstein B, Kinzler KW, Velculescu VE: The consensus coding sequences of human breast and colorectal cancers. Science 2006, 314(5797):268-274.

13. Yoshida BA, Dubauskas Z, Chekmareva MA, Christiano TR, Stadler WM, Rinker-Schaeffer CW: Mitogen-activated protein kinase kinase 4/stressactivated protein/Erk kinase 1 (MKK4/SEK1), a prostate cancer metastasis suppressor gene encoded by human chromosome 17. Cancer Res 1999, 59(21):5483-5487.

14. Wang $L$, Pan $Y$, Dai JL: Evidence of MKK4 pro-oncogenic activity in breast and pancreatic tumors. Oncogene 2004, 23(35):5978-5985.

15. Nakayama K, Nakayama N, Davidson B, Katabuchi H, Kurman RJ, Velculescu VE, Shih le M, Wang TL: Homozygous deletion of MKK4 in ovarian serous carcinoma. Cancer Biol Ther 2006, 5(6):630-634.

16. Spillman MA, Lacy J, Murphy SK, Whitaker RS, Grace L, Teaberry V, Marks JR, Berchuck A: Regulation of the metastasis suppressor gene MKK4 in ovarian cancer. Gynecol Oncol 2007, 105(2):312-320.

17. Yamada SD, Hickson JA, Hrobowski Y, Vander Griend DJ, Benson D, Montag A, Karrison T, Huo D, Rutgers J, Adams S, Rinker-Schaeffer CW: Mitogen-activated protein kinase kinase 4 (MKK4) acts as a metastasis suppressor gene in human ovarian carcinoma. Cancer Res 2002, 62(22):6717-6723.

18. Gorringe KL, Ramakrishna M, Williams LH, Sridhar A, Boyle SE, Bearfoot JL, Li J, Anglesio MS, Campbell IG: Are there any more ovarian tumor suppressor genes? A new perspective using ultra high-resolution copy number and loss of heterozygosity analysis. Genes Chromosomes Cancer 2009, 48(10):931-942

19. Mullenbach R, Lagoda PJ, Welter C: An efficient salt-chloroform extraction of DNA from blood and tissues. Trends Genet 1989, 5(12):391.

20. Gorringe KL, Choong DY, Williams LH, Ramakrishna M, Sridhar A, Qiu W, Bearfoot IL, Campbell IG: Mutation and methylation analysis of the chromodomain-helicase-DNA binding 5 gene in ovarian cancer. Neoplasia 2008, 10(11):1253-1258.

21. Rozen S, Skaletsky H: Primer3 on the WWW for general users and for biologist programmers. Methods Mol Biol 2000, 132:365-386.

22. Ikediobi ON, Davies H, Bignell G, Edkins S, Stevens C, O'Meara S, Santarius T, Avis T, Barthorpe S, Brackenbury L, Buck G, Butler A, Clements J, Cole J, Dicks E, Forbes S, Gray K, Halliday K, Harrison R, Hills K, Hinton J, Hunter C, Jenkinson A, Jones D, Kosmidou V, Lugg R, Menzies A, Mironenko T, Parker A, Perry J, et al: Mutation analysis of 24 known cancer genes in the NCI-60 cell line set. Mol Cancer Ther 2006, 5(11):2606-2612.

23. Ward BG, Wallace K, Shepherd JH, Balkwill FR: Intraperitoneal xenografts of human epithelial ovarian cancer in nude mice. Cancer Res 1987, 47(10):2662-2667.

24. Tsao SW, Wong N, Wang $X$, Liu Y, Wan TS, Fung LF, Lancaster WD, Gregoire L, Wong YC: Nonrandom chromosomal imbalances in human ovarian surface epithelial cells immortalized by HPV16-E6E7 viral oncogenes. Cancer Genet Cytogenet 2001, 130(2):141-149.

25. Ziauddin J, Sabatini DM: Microarrays of cells expressing defined cDNAs. Nature 2001, 411(6833):107-110.

26. Simpson K, Selfors LM, Bui J, Reynolds A, Leake D, Khvorova A, Brugge JS: Identification of genes that regulate epithelial cell migration using an siRNA screening approach. Nat Cell Biol 2008, 10(9):1027-1038.
27. Bearfoot JL, Choong DY, Gorringe KL, Campbell IG: Genetic analysis of cancer-implicated MicroRNA in ovarian cancer. Clin Cancer Res 2008, 14(22):7246-7250.

28. Gorringe KL, George J, Anglesio MS, Ramakrishna M, Etemadmoghadam D, Cowin P, Sridhar A, Williams LH, Boyle SE, Yanaihara N, Okamoto A, Urashima M, Smyth GK, Campbell IG, Bowtell DD: Copy number analysis identifies novel interactions between genomic loci in ovarian cancer. Plos one 2010, 5(9).

29. Ramakrishna M, Williams LH, Boyle SE, Bearfoot JL, Sridhar A, Speed TP, Gorringe KL, Campbell IG: Identification of candidate growth promoting genes in ovarian cancer through integrated copy number and expression analysis. PLoS One 2010, 5(4):e9983.

30. Etemadmoghadam D, deFazio A, Beroukhim R, Mermel C, George J, Getz G, Tothill R, Okamoto A, Raeder MB, Harnett P, Lade S, Akslen LA, Tinker AV, Locandro B, Alsop K, Chiew YE, Traficante N, Fereday S, Johnson D, Fox S, Sellers W, Urashima M, Salvesen HB, Meyerson M, Bowtell D: Integrated genome-wide DNA copy number and expression analysis identifies distinct mechanisms of primary chemoresistance in ovarian carcinomas. Clin Cancer Res 2009, 15(4):1417-1427.

31. Tothill RW, Tinker AV, George J, Brown R, Fox SB, Lade S, Johnson DS, Trivett MK, Etemadmoghadam D, Locandro B, Traficante N, Fereday S, Hung JA, Chiew YE, Haviv I, Gertig D, DeFazio A, Bowtell DD: Novel molecular subtypes of serous and endometrioid ovarian cancer linked to clinical outcome. Clin Cancer Res 2008, 14(16):5198-5208.

32. Yeasmin S, Nakayama K, Rahman MT, Rahman M, Ishikawa M, Katagiri A lida K, Nakayama N, Miyazaki K: Loss of MKK4 expression in ovarian cancer: A potential role for the epithelial to mesenchymal transition. Int $J$ Cancer 2010

33. Kan Z, Jaiswal BS, Stinson J, Janakiraman V, Bhatt D, Stern HM, Yue P, Haverty PM, Bourgon R, Zheng J, Moorhead M, Chaudhuri S, Tomsho LP Peters BA, Pujara K, Cordes S, Davis DP, Carlton VE, Yuan W, Li L, Wang W, Eigenbrot C, Kaminker JS, Eberhard DA, Waring P, Schuster SC, Modrusan Z, Zhang Z, Stokoe D, de Sauvage FJ, et al: Diverse somatic mutation patterns and pathway alterations in human cancers. Nature 2010 466(7308):869-873.

\section{Pre-publication history}

The pre-publication history for this paper can be accessed here: http://www.biomedcentral.com/1471-2407/11/173/prepub

doi:10.1186/1471-2407-11-173

Cite this article as: Davis et al: Analysis of the Mitogen-activated protein kinase kinase 4 (MAP2K4) tumor suppressor gene in ovarian cancer. BMC Cancer 2011 11:173.

\section{Submit your next manuscript to BioMed Central and take full advantage of:}

- Convenient online submission

- Thorough peer review

- No space constraints or color figure charges

- Immediate publication on acceptance

- Inclusion in PubMed, CAS, Scopus and Google Scholar

- Research which is freely available for redistribution 